\title{
Encapsulated of Red Beet Colour Changes During Spray Drying
}

\author{
Gulsever Neslihan, Karatas Sukru \\ Engineering Faculty, Food Engineering Department, İstanbul Aydın University, Istanbul, Turkey
}

\section{Email address:}

neslihangulsever@stu.aydin.edu.tr (G. Neslihan), sukrukaratas@aydin.edu.tr (K. Sukru)

\section{To cite this article:}

Gulsever Neslihan, Karatas Sukru. Encapsulated of Red Beet Colour Changes During Spray Drying. International Journal of Food Engineering and Technology. Vol. 4, No. 2, 2020, pp. 13-17. doi: 10.11648/j.ijfet.20200402.11

Received: July 23, 2020; Accepted: August 5, 2020; Published: August 27, 2020

\begin{abstract}
In this research, the red beet concentrates were encapsulated with maltodextrin (DE10) citric acid, monoglycerides, lecitin and sunflower oil then spray dried at 150,160 , and $170^{\circ} \mathrm{C}$. The color of each spray dried powder was diluted to one brix and analysed by spectrophotometer at $510 \mathrm{~nm}$ in duplicate which was compared to initial color of concentrated red beet. The deterioration of color loses were behaved first-order reaction and the reaction rates $(\mathrm{k})$ were determined as $0.02,0.039$ and $0.068 \mathrm{sn}^{-1}$ at 150,160 , and $170^{\circ} \mathrm{C}$ respectively. Higher spray drying air temperature results in high-speed drying. However, it was determined that high inlet air temperatures caused more pigment loss. From reaction rates the activation energy was estimated about $21.16 \mathrm{Kcal} / \mathrm{mol}$ by using of Arrhenius equations. Determined during the degradation of pigments by heat, $\mathrm{t}_{1 / 2}$ values were found as $31.25 \mathrm{sec}, 17.76 \mathrm{sec}, 10.01 \mathrm{sec}$ at 150,160 , and $170^{\circ} \mathrm{C}$, respectively. It was determined that the color of red beet was so sensitive during spray drying. It was also determined that reaction rate was about two times faster at each drying temperature raise up $10^{\circ} \mathrm{C}$, it was also size of the encapculated powder were determined between 1-10 $\mu \mathrm{m}$ by scanning electron microscope.
\end{abstract}

Keywords: Red Beet, Encapsulation, Spray Dry, Activation Energy, Electron Microscope

\section{Introduction}

The colour pigments found in foods deteriorate as a result of the processing techniques and heat treatments applied to the product, and subsequent colour losses occur. For this reason, synthetic or natural colouring agents are used to improve the appearance of the product, increase its quality and provide colour uniformity in different productions.

Beetroot (Beta Vulgaris L.) is used as a natural colouring for red tones in the food industry. Colour materials obtained from beets is used as a Colourant in products such as tomato soups, jams, yogurt, pudding, breakfast cereals, bakery products, confectionery, sausages and meat [1].

The Colour of red beet is due to its high betalain content ( $~$ $200 \mathrm{mg} / 100 \mathrm{~g}$ fresh weight). Betalains are water-soluble nitrogen-containing pigments consisting of two structural groups. These pigments are red-purple betacyanine and yellow-orange betaxanthines. Their content in the roots depends on the degree of maturity, variety and climatic conditions. Betanin constitutes $75-78 \%$ of the total content of betacyanin pigments and represents $95 \%$ of all red pigments in isobetanin and beet juice. Betaxanthines include vulgaxanthines (vulgaxanthin I and II) [2].

Natural Colour materials have low stability compared to synthetic ones. As with other natural Colour pigments, the Colour pigments in beets are affected by factors especially such as $\mathrm{pH}$, oxygen presence, water activity, temperature and light $[3,4]$.

Encapsulation is one of the methods used to protect compounds of natural origin. The purpose of this method is to minimize the interaction between the environment and the components by creating an obstacle around the coating materials and sensitive components. By encapsulation of natural colour substances, increasing stability, long shelf life and high nutritional value food products are provided [5].

There are various techniques and coating materials that can be used in encapsulation to overcome the instability, solubility and usage problems of natural food colourants. The most important step in the encapsulation process is to choose a suitable coating material [6]. Different dextrose 
equivalent (DE) maltodextrins, carbohydrates such as sucrose, amylose, polydextrose; proteins such as gelatine, whey proteins (caseinate, casein); lipids such as candles, glycerine; gums (gum arabic, alginates) are used as coating materials [7].

There are several methods for encapsulation. These methods include spray drying, spray cooling, fluidized bed coating, coacervation, extrusion coating, can be listed as rotational suspension separation. The most common method among these methods is spray drying [8].

Spray drying is a process in which an emulsion containing encapsulated material is atomized in a hot air circulating drying chamber. Contact of the solution with hot air causes the evaporation of water, leading to the production of microcapsules [9]. With spray drying method, it provides a powder product characterized by various physical properties depending on drying parameters such as encapsulation, carrier concentration, solution flow rate, temperature speed $[10,11]$.

The purposes of this research was to investigate the red color of beet concentrate changes when was encapsulated with tapioca maltodextrin (DE10), citric acid, monoglycerides and lecithin and sunflower oil during spray drying at 150,160 and $170^{\circ} \mathrm{C}$ and also to determine encapsulated powder size by scanning electron microscope.

\section{Material and Method}

\subsection{Material}

Red beet concentrate used as a raw material in the thesis study is provided by Göknur Foodstuffs Import Trade and Industry Inc. Afyon, Turkey. Tapioca Maltodextrin (Dextrose equivalent (DE) 10) selected as a coating material, Modersnist Pantry, Chloe Allegra was provided by Holding LLC (USA), sitric acid monoglycerides by Aspek Chemistry Food Import and Export Ind. Trade Co. Ltd. and lecithin is provided by Kimbiotek Chemical Substances Ind. Trade Inc.

\subsection{Preparation of Feeding Emulsion}

The emulsion contains $51.6 \%$ beet concentrate, $20 \%$ tapioca maltodextrin, $18 \%$ sunflower oil, $6 \%$ citric acid mono digycerides, $4 \%$ lecithin and $0.1 \%$ salt. The specified ratio of tapioca maltodextrin is kept in distilled water in an ultrasonic water bath until it is completely dissolved. Sitric acid monoglycerides was mixed with magnetic stirring until it dissolved in sunflower oil. Then lecithin was added to the mixture. The prepared mixes were added to the beet concentrate.

To mix the coating materials and concentrate homogeneously, the final water-soluble dry matter content (Brix) of the mixture was adjusted to $15 \%$ and homogenized in the armfield FT 9 pressurized homogenizer under 50 bar pressure.

\subsection{Spray Drying Process}

The spray drying process was carried out using a lab scale Lab -Plant SD40 Basic spray dryer (Lab Plant Ltd., UK). The feed emulsion was pumped into the atomizer with a peristaltic pump. Atomization was carried out using two fluid nozzles using compressed air. The compressed air flow rate was controlled by a variable area flow meter. The main chamber and the cyclone are made of thick transparent glass. After the inlet drying air passed through the heater, it flowed simultaneously with the spray from the main chamber. The dried powder samples were collected from the cyclone floor $[12,13]$.

The controlled parameters of the spray dryer are the feed rate, atomizer pressure, the flow rate of the drying air (aspirator setting), the feed concentration and temperature, the inlet air temperature. The outlet air temperature of the dryer cannot be adjusted with a temperature regulator such as the inlet air temperature. The outlet air temperature is due to the combination of inlet air temperature, pump setting, supply concentration and aspirator setting [13].

In all experiments, the atomizer pressure, feed rate, and feed temperature were maintained at $5 \pm 0.1 \mathrm{bar}, 4 \mathrm{ml} / \mathrm{min}$ and $25 \pm 0.5^{\circ} \mathrm{C}$, respectively. Three different inlet air temperatures $\left(150,160,170^{\circ} \mathrm{C}\right)$ were used. Outlet air temperatures (Toutlet) were monitored constantly. The inlet and outlet air temperatures were read from the digital display on the dryer control panel and recorded manually.

\subsection{Investigation of Red Colour Pigments by Spectrophotometer}

Pure water was added to the powders obtained by spray dryer at different drying temperatures and mixed for 10 minutes. The mixture was then filtered through filter paper. Samples were prepared in different brixes using Abbe refractometer.

Samples were placed in the cuvette and measured on a UV-Vis spectrophotometer. Absorbance values were determined. Calibration curve was created by measuring 510 nm wavelength of samples prepared in different brixes.

After the emulsion prepared with red beet concentrate and coating materials was dried at different drying temperatures in the spray dryer, the reaction rate constant and activation energy values were calculated by examining the change in red Colour according to Lambert Beer law.

\subsection{Investigation of the Size and Microstructure of Microencapsulated Powders}

Emission scanning electron microscopy (FEI QUANTA 450 FEG ESEM SEM) was used to examine the morphological properties of spray-dried powders. Thanks to the ESEM mode, the device provides ease of inspection of dusty, oily and organic structures without any coating required. The powders were attached to the double-sided adhesive tape pieces mounted on the SEM studs. Then scans were done at $\mathrm{x} 500, \mathrm{x} 1000, \mathrm{x} 2000$ magnification. During the micrograph, $20 \mathrm{kV}$ acceleration potential and 5 spotlights 
were used.

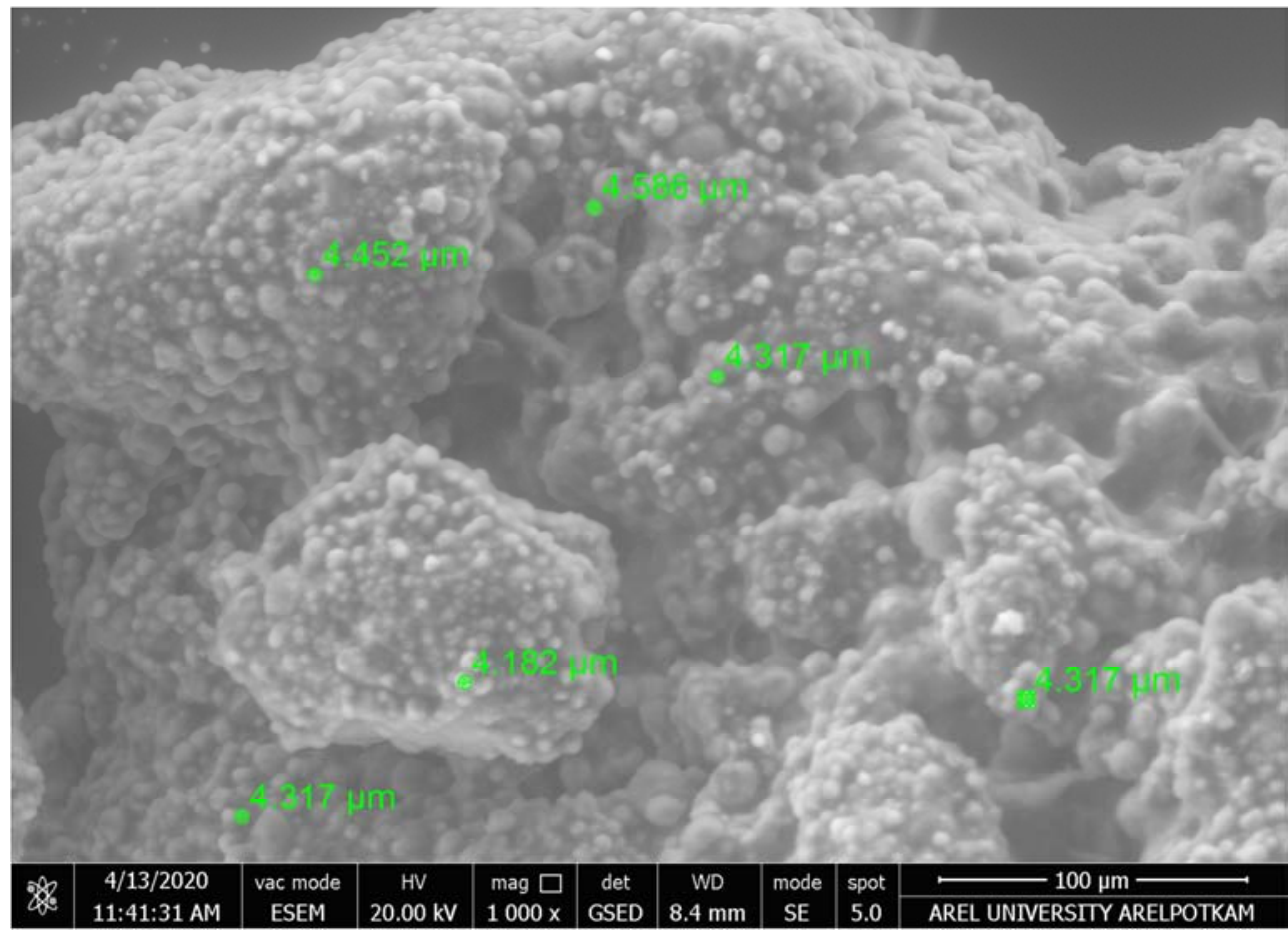

Figure 1. Encapsulated beetroot powders within tapioca maltodextrin Scanning electron microscope images.

\section{Result and Discussion}

After the emulsion prepared with red beet concentrate and coating materials was dried at different drying temperatures in the spray dryer, the reaction rate constant $\mathrm{k}_{1}$ and activation energy values were calculated by examining the change in red colour according to Lambert Beer law. The study was conducted in two parallels and averaged.

The calibration curve of the samples prepared in different brix was determined. Calibration graph and regression equation were created with excel.

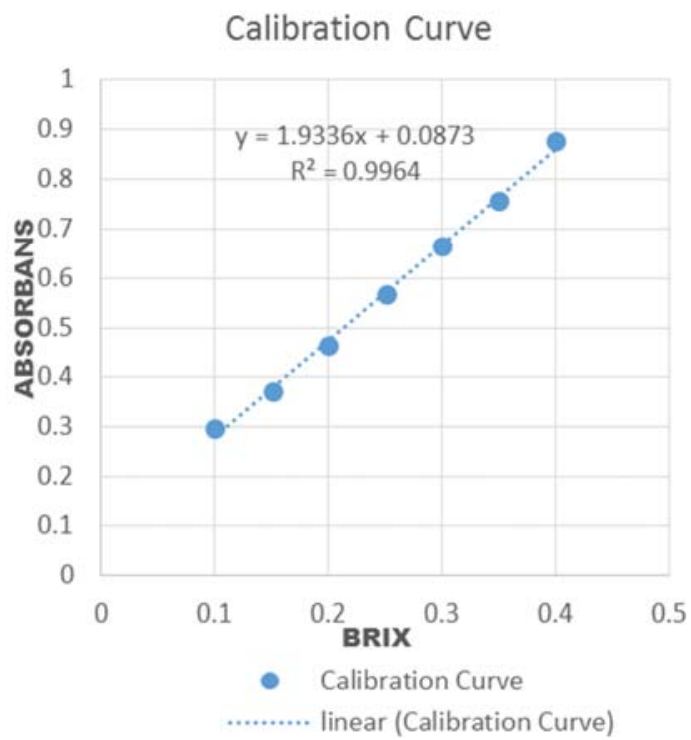

Figure 2. Emulsion Absorbance related with concentration.
The reaction rate increases with increasing temperature, which is first parameterized by Arrhenius. The change between reaction rate and temperature is expressed by the Arrhenius equation.

$$
\mathrm{k}=\mathrm{Ae} \mathrm{e}^{-\mathrm{Ea} / \mathrm{RT}}
$$

$\mathrm{k}=$ reaction rate constant
A: Reference Factor
$\mathrm{Ea}=$ Activation Energy $(\mathrm{cal} / \mathrm{mol})$
$\mathrm{R}=$ Gas Constant $(1.98 \mathrm{cal} / \mathrm{mol} \mathrm{K})$
T: Temperature (Kelvin)

As indicated in Figures 3-5, k values were calculated for each temperature. Activation energy was determined from the relationship between lnk values and 1/T temperature.

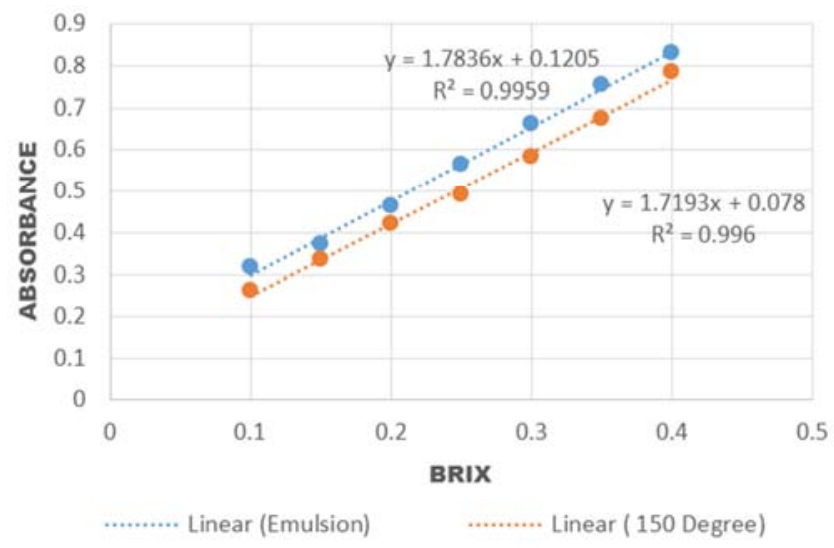

Figure 3. Absorbance at $150^{\circ} \mathrm{C}$. 


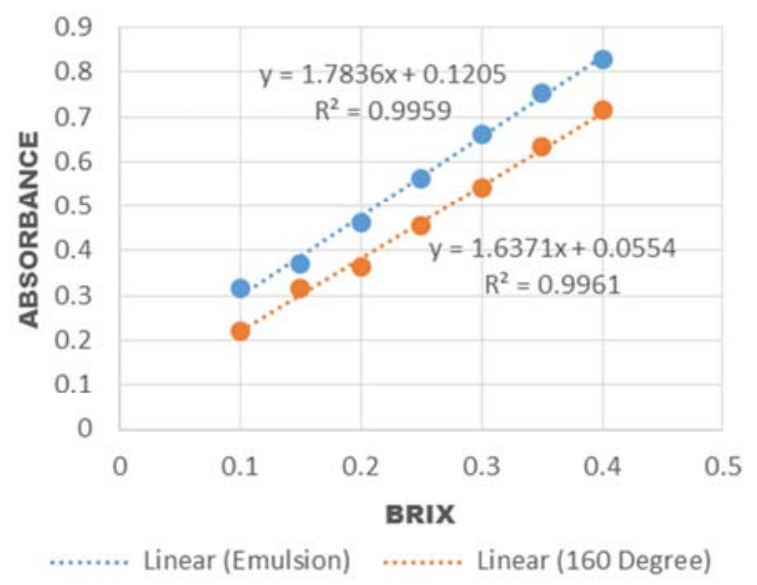

Figure 4. Absorbance at $160^{\circ} \mathrm{C}$.

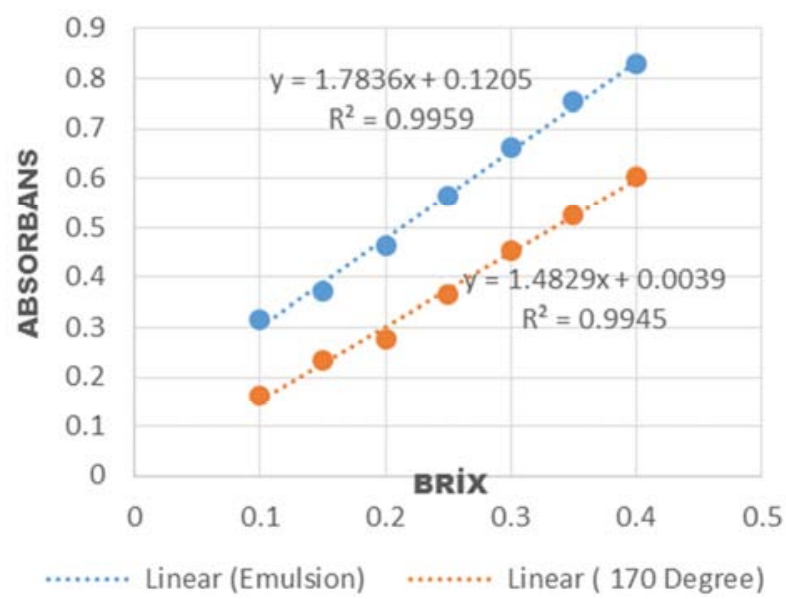

Figure 5. Absorbance at $170^{\circ} \mathrm{C}$.

$$
\ln \left(\mathrm{A}_{0} / \mathrm{A}\right)=\mathrm{k} \cdot \mathrm{t}
$$

Here;

$\mathrm{A}_{0}$ : Absorbance of Emulsion

A: Absorbance of spray dried one brix powder

$\mathrm{k}$ : Reaction Speed Constant $\left(\mathrm{s}^{-1}\right)$

t: time second (s)

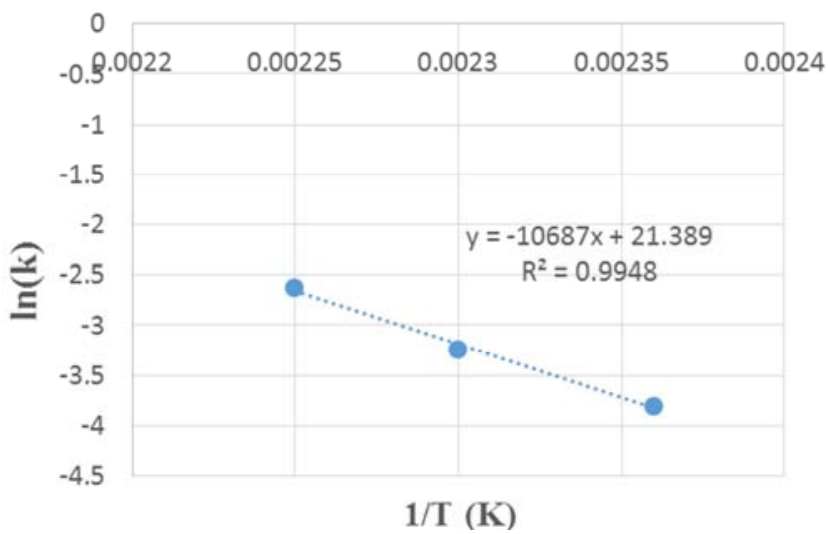

Figure 6. $\ln (k)$ v.s $-1 / T$.

Activation Energy

Slope $=-E_{a} / R$

$-10687=E_{a} / 1.98$
$\mathrm{E}_{\mathrm{a}}=21.160 \mathrm{kcal} / \mathrm{mol}$.

Table 1. Reaction Speed Constants and lnk Values.

\begin{tabular}{lll}
\hline Temperature (K) & Reaction Speed Constant $\left(\mathbf{K}, \mathbf{s n}^{-1}\right)$ & Ln $(\mathbf{k})$ \\
\hline 443 & 0.068 & -2.63 \\
433 & 0.039 & -3.27 \\
423 & 0.022 & -3.81 \\
\hline
\end{tabular}

As a result of the kinetic study, it was determined that there was a deterioration in the red beet colour pigments at all drying temperatures and this deterioration corresponded to the first- degree reaction kinetics.

The deterioration of color loses of reaction rates were determined as $0.02,0.039$ and $0.068 \mathrm{~s}^{-1}$ during spray drying at 150,160 and $170^{\circ} \mathrm{C}$ respectively which was behaved firstorder reaction. The activation energy was estimated about $21.16 \mathrm{Kcal} / \mathrm{mol}$ using of Arrhenius equations, it was also found that deterioration rate was 2 times faster at each drying temperature raised up to $10^{\circ} \mathrm{C}$.

The similar research was carried out by other authers; Saguy, Kopelman and Mizrahi [15], for betanin extract at 60, 75,81 and $86^{\circ} \mathrm{C}$, the activation energy was determined about $20.4 \mathrm{kcal} / \mathrm{mol}$ this investigation is parallel with our results. It was also reported that degradation related with temperature in red beet and purple pitaya juices were behaved to the first order reaction $[15,16]$.

Crab Apple (Malus Floribunda) juice investigated the encapsulation of anthocyanins with coating materials of different types and proportions and their thermal stability at different temperatures [17]. Maltodextrin (MD), gum Arabic (GA) and MD: AG (1: 1) were used as coating material. Speed constants of maltodextrin at $70,80,90^{\circ} \mathrm{C}$ providing the highest protection for anthocyanins as $1.45,2.75$ ve 5.05 $\mathrm{x} 10^{-3}$ minutes. The activation energy was found as 17,6 $\mathrm{kcal} / \mathrm{mol}$. The difference in this research is thought to be due to the product types used or the temperature difference.

In the thermal stability study of Black Carrot Anthocyanins, it was emphasized that high activation energy makes the reactions more sensitive to temperature change [18]. Besides, it has been stated that the activation energy values for the thermal degradation of water-soluble pigments are between $15.02-30.5 \mathrm{kcal} / \mathrm{mol}$ [19].

In the study conducted to examine the effect of spray drying conditions on the physical properties of pitaya water powder, the most suitable air inlet temperature was determined as $150^{\circ} \mathrm{C}$. Low drying temperatures $\left(150^{\circ} \mathrm{C}\right)$ have been found to promote higher yields and red-purple Colour retention during spray drying. It was determined that the results obtained were in harmony with our research [20].

In the study, it is aimed to reduce losses in red beet Colour pigments with the encapsulation process. It is of great importance to determine which parameters and which coating materials can be protected with Colour pigments. Tests can be made to increase the amount of encapsulated pigment using different coating materials and encapsulated powder size were determined between $1-10 \mu \mathrm{m}$ by using of scanning electron microscope. 


\section{Conclusion}

It was determined that the color of red beet was so sensitive during spray drying

The deterioration of color loses of reaction rates were determined as $0.02,0.039$ and $0.068 \mathrm{~s}^{-1}$ during spray drying at 150,160 and $170^{\circ} \mathrm{C}$ respectively which was behaved firstorder reaction. The activation energy was estimated about $21.16 \mathrm{Kcal} / \mathrm{mol}$ using of Arrhenius equations, it was also found that deterioration rate was 2 times faster at each drying temperature raised up to $10^{\circ} \mathrm{C}$.

SEM micrograph analyses indicated that the particle size of the encapsulated beet powders, which were spray-dried at $150^{\circ} \mathrm{C}$, was about $1 \mu \mathrm{m}$ to $10 \mu \mathrm{m}$.

\section{References}

[1] Khan, M. I. (2016). Stabilization of Betalains: A Review. Food Chemistry 197 1280-1285.

[2] Azeredo, M. C. (2009) Betalains: Properties, Sources, Applications, and Stability-A Review. International Journal of Food Science and Technology, 44, 2365-2376.

[3] Ravichandrana, K., Nay Min Min Thaw Sawa, Adel A. A., Mohdalya, Ahmed, M. M., Gabra, Kastella, A. Riedela, H. Caia, Z. Knorrb, D. Smetanska, I. (2013). Impact of Processing of Red Beet on Betalain Content and Antioxidant Activity. Food Research International, S: 670-675.

[4] Herbach, K. M., Stintzing, F. C., Carle, R. (2006). Betalain stability and degradation-structural and chromatic aspects. Journal of Food Science, 71 (4), 41-50.

[5] Gibbs, B. F., Kermasha, S., Alli, I., and Mulligan, C., N. (1999). Encapsulation in the food industry: a review, International Journal of Food Sciences and Nutrition, 50, 213-224.

[6] Shahidi, F. and Han, X-Q. (1993), Encapsulation of Food Ingredients, Critical Reviews in Food Science and Nutrition, 33 (6), 501-547.

[7] Dubey, R., Shami, T. C., Bhasker-Rao, K. U. (2009). Microencapsulation Technology and Applications. Defence Science Journal, 59 (1), 82-95.

[8] Desai, K. G. H. ve Park, H. J. (2005). Recent developments in microencapsulation of food ingredients. Dry. Technol. Say1 23, 1361-1394.
[9] Gharsallaoui, A., Gae“lle Roudaut, O., Chambin, A. V., Saurel, R. (2007). Applications of spray-drying in microencapsulation of food ingredients: An overview. Food Research International, 40, 1107-1121.

[10] Janiszewska, E. (2014). Microencapsulated beetroot juice as a potential source of betalain. Powder Technology, 64, 190-196.

[11] Janiszewska, E., Wlodarczyk, J. (2012). Influence of spray drying conditions on beetroot pigments retention after microencapsulation process. Acta Agrophysica, 20 (2), 343356.

[12] Athanasia M., Goula and Konstantinos G., Adamopoulos (2003). Spray Drying Performance of a Laboratory Spray Dryer for Tomato Powder Preparation. Drying Technology: An International Journal, Vol. 21, No. 2, 1273-1289.

[13] Cai, Y. Z., Corke, H. (2000). Production and Properties of Spray-dried Amaranthus Betacyanin Pigments. Journal of Food Science, 65 (6), 1248-1252.

[14] Labuza, T. P. (1984), Application of Chemical-Kinetics to Deterioration of Foods, Journal of Chemical Education, 61 (4), 348-358.

[15] Saguy, Saguy, I; Kopelman, I. J. and Mizrahi S. (1978). Thermal Kinetic Degradation of Betanin and Betalamic J. Agric. Food Chem., Vol. 26, No. 2.

[16] Von Elbe, J. H., I. Y. Maing and C. H. Amundson. (1974) Colour stability of betanin. J. Food Science., 39, 334-337.

[17] Yeşil, S. (2018). Süs Elması Antosiyaninlerinin Enkapsülasyonu ve Termal Stabilitesinin Belirlenmesi. Yüksek Lisans Tezi, Selçuk Üniversitesi Fen Bilimleri Entitüsü, 48.

[18] Kirca, A., Ozkan, M. ve Cemeroglu, B. (2006). Stability of black carrot anthocyanins in various fruit juices and nectars. Food Chemistry, 97 (4), 598-605.

[19] Nielsen, S. S., Marcy, J. E. ve Sadler, G. D. (1993). Chemistry of aseptically processed foods, In: Principles of Aseptic Processing and Packaging, Eds: Chambers, J. V. ve Nelson, P. E., Washington, DC: Food Processors Institute, p, 257.

[20] Garcia-Lucas, K. A., Mendez-Lagunas, L. L., RodriguezRaminez, J., Campanella, O. H., Patel, B. K., Barriada-Bernal, L. G. (2016). Physical properties of spray dryed Stenocereus griseus pitaya juice powder. Journal of Food Process Engineering, 40, 1-9. 